\title{
Hydroxylamine catalyzed Nazarov cyclizations of divinyl ketones ${ }^{\dagger}$
}

Joseph Z. Hamilton, Nathaniel T. Kadunce, Michael D. McDonald, Laura Rios

Albert R. Matlin*

Department of Chemistry, Oberlin College, Oberlin, $\mathrm{OH}$ 44074, United States

ABSTRACT: The first examples of iminium catalyzed Nazarov cyclizations of divinyl ketones are presented. Experiments describing hydroxylamine catalysis of the cyclization of eight $\alpha-$ alkoxy divinyl ketones (60-79\% yield) and one unactivated divinyl ketone (38\% yield) are reported. Phenyl substitution at the $\beta$-position of the divinyl ketone inhibits cyclization, whereas $\beta$-alkyl substituted $\alpha$-alkoxy divinyl ketones readily cyclize.

Keywords: Nazarov cyclization, hydroxylamine catalysis, iminium ions, divinyl ketones

'Dedicated to Professor Hilton Weiss on his $80^{\text {th }}$ birthday.

* Corresponding author. Tel: +01 440775 8308; fax +01 4407756682

E-mail address: amatlin@oberlin.edu

\section{Introduction}

The Nazarov cyclization continues to be an area of active interest due its utility in the synthesis of substituted cyclopentenones. ${ }^{1}$ Recent studies have focused on new catalysts, ${ }^{2}$ new substrates, ${ }^{3}$ enantioselective cyclizations, ${ }^{4}$ interrupted cyclizations/ tandem reactions ${ }^{5}$ and applications to the synthesis of natural products. ${ }^{6}$ Despite the overwhelming success of pyrrolidine-based organocatalysts to promote a wide range of reactions involving both enals and enones, there are no examples of iminium ion catalyzed Nazarov cyclizations of divinyl ketones in the literature. ${ }^{7}$ There have been a few examples of Nazarov cyclizations with other substrates reported that involve imino/iminium ions, but these reactions require stoichiometric amounts of the reactants. ${ }^{8}$ For example, Tius and co-workers have reported a chiral bifunctional primary/secondary amine catalyst that promotes the cyclization of $\alpha$-ketoenones with high er's, but the reaction requires one equivalent of the diamine (Scheme 1). ${ }^{8 \mathrm{a}}$ They proposed that the cyclization involves formation of an enamine-iminium ion that does not readily hydrolyze under the reaction conditions.

Scheme 1. Diamine Catalysis of $\alpha$-Ketoenones Nazarov Cyclizations.

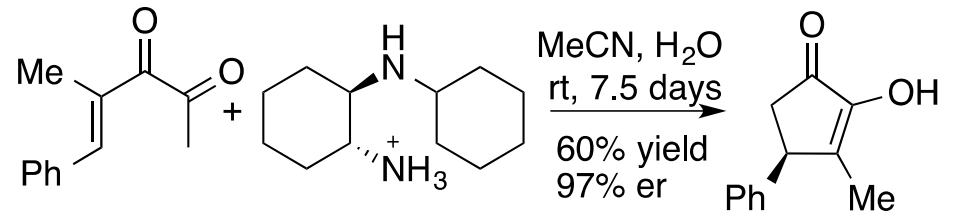


The absence of reports of amine-catalyzed Nazarov cyclization with divinyl ketones may be the result of a computational study published by Smith. ${ }^{9} \mathrm{He}$ concluded that the ammonia catalyzed Nazarov cyclization would have an unfavorable equilibrium between the divinyl iminium ion $\mathbf{1}$ and the cyclized product $\mathbf{2}$ (Scheme 2). Considering this issue we hypothesized that as long as the activation barrier for the formation of iminium ion $\mathbf{1}$ was not prohibitive, then an unfavorable equilibrium between intermediates 1 and $\mathbf{2}$ could be drawn off in the next step (formation of iminium ion 3 ), which should be energetically favorable. Here we report our initial studies directed at developing an amine-catalyzed Nazarov cyclization of divinyl ketones.

Scheme 2. Iminium Catalysis of a Divinyl Ketone.

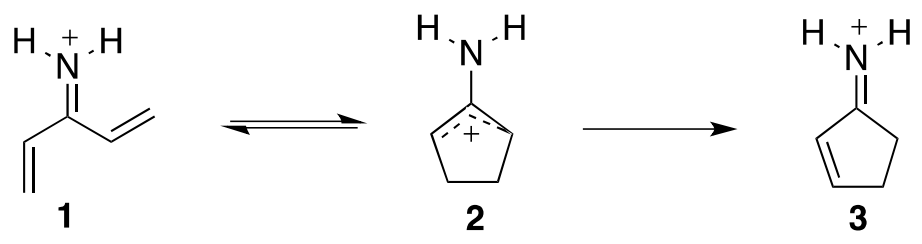

\section{Results and discussion}

We began our investigation with a DFT computational study of the iminium Nazarov cyclization reaction in Scheme 2. Using the B3LYP functional with 6-31G(d) basis set we calculated the cyclization step of $\mathbf{1}$ to $\mathbf{2}$ to have a $\Delta G^{\circ}$ value of $5.3 \mathrm{kcal} / \mathrm{mol}$, which is similar to that reported by Smith. However, as we anticipated, the overall transformation of $\mathbf{1}$ to $\mathbf{3}$ is calculated to be highly favorable with a $\Delta G^{\circ}$ of $-23.2 \mathrm{kcal} / \mathrm{mol}$.

Encouraged by these calculations we initiated an experimental study to develop an amine-catalyzed Nazarov cyclization of divinyl ketones by examining three pyrrolidine based secondary amines catalysts (pyrrolidine hydroperchlorate, DL-proline, and L-proline benzyl ester hydrochloride) with the "activated" $\alpha$-alkoxy substrate 4 (Scheme 3). We screened these catalysts (20 mol \%) under a variety of reaction conditions (solvents: methanol, methanol with $5 \%$ water, ethanol, ethanol with 5\% water, dichloromethane, acetonitrile; reaction temperature: $\mathrm{rt}$ to $70^{\circ} \mathrm{C}$ for up to 3 days). We failed to observe cyclized products under any of these conditions. Instead, these reactions led to either decomposition of the divinyl ketone or returned the starting material largely intact. We also found that the MacMillan catalyst, (5S)-2,3,3-trimethyl-5- 
benzyl-4-imidazolinone, was unsuccessful in cyclizing 4 ( $20 \mathrm{~mol} \%$ catalyst, ethanol, $70^{\circ} \mathrm{C}, 15$ h).

Scheme 3. Nazarov cyclization of "activated" divinyl ketones.

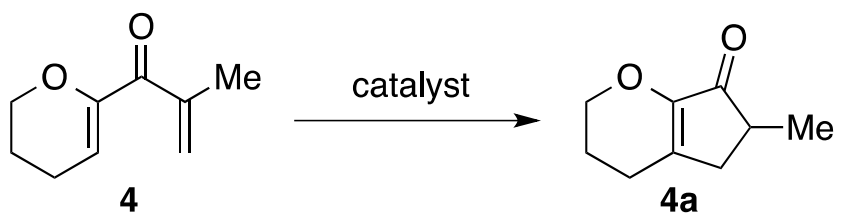

The failure of pyrrolidine catalysts is likely due to their inability to form the initial iminium ions. While these catalysts work well with reactions involving enals and enones, divinyl ketones such as $\mathbf{4}$ should be less susceptible to nucleophilic attack due to the increased electron density in the $\pi$-system with the addition of the second C-C double bond. Tomkinson has reported that secondary hydroxylamines and substituted hydrazines are effective catalysts for the Diels-Alder reaction. ${ }^{10}$ These catalysts should be more nucleophilic than simple amines due to the " $\alpha$ effect". ${ }^{11}$ Inspired by these reports, we decided to investigate the efficacy of hydroxylamine hydrochloride as a catalyst for the Nazarov cyclization. We chose to examine hydroxylamine for three reasons: hydroxylamine is know to reversibly form oximes under acidic conditions and the combination of the $\alpha$-effect with the small steric profile of the primary amine should facilitate nucleophilic reactions. ${ }^{12}$

Reaction of divinyl ketone $\mathbf{4}$ with $20 \mathrm{~mol} \%$ of hydroxylamine hydrochloride in ethanol for 16 hours at $70^{\circ} \mathrm{C}$ resulted in the formation of the cyclized product $4 \mathbf{a}$ in $67 \%$ isolated yield. To the best of our knowledge this represents the first use of hydroxylamine as catalyst and the first example of an iminium ion-catalyzed Nazarov cyclization of a divinyl ketone. In order to rule out the possibility that the Brønsted acid properties of hydroxylamine hydrochloride ( $\mathrm{pKa}$ 5.94) were responsible for the catalysis, we ran two control reactions using acetic acid ( $\mathrm{pKa}$ 4.76) and N,N-diethylhydroxylamine oxalate ( $\mathrm{pKa} \sim 5.7)$ with divinyl ketone $4 .^{13}$ No reaction was observed after heating 4 at $70^{\circ} \mathrm{C}$ in ethanol for 15 hours in the presence of $20 \mathrm{~mol} \%$ of acetic acid or $20 \mathrm{~mol} \%$ diethylhydroxylamine oxalate. These results are consistent with the interpretation that the reaction occurs by way of iminium ion catalysis.

We propose that the reaction follows the catalytic cycle illustrated in Scheme 4. The reaction is initiated by condensation of hydroxylamine with divinyl ketone 5 to give the iminium ion $\mathbf{6}$. Conrotatory ring closure of $\mathbf{6}$ produces cyclopentyl allyl cation $\mathbf{7}$, which isomerizes via 
elimination of a proton followed by protonation at the $\alpha$-carbon to yield $\mathbf{8}$. Hydrolysis produces the isolated cyclopentenone product 9 and regenerates the hydroxylamine catalyst.

Scheme 4. Proposed catalytic cycle for hydroxylamine-catalyzed Nazarov cyclizations.

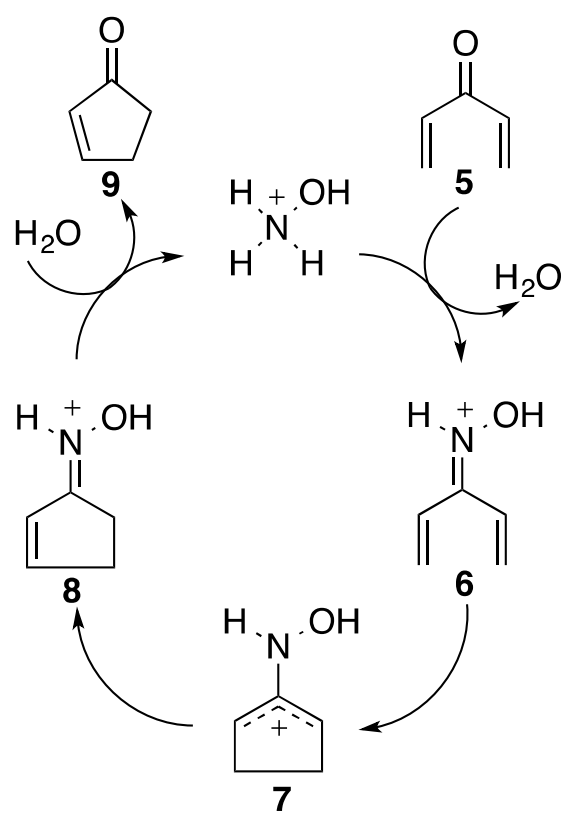

Table 1 lists the divinyl ketones that we have subjected to hydroxylamine catalysis. With the exception of the unactivated divinyl ketone $\mathbf{1 1}$ and $\beta$-phenyl divinyl ketone $\mathbf{9}$, the reactions produce cyclopentenones in good yields (60-79\%). ${ }^{14}$ The lack of reactivity of 9 probably arises from the $\beta$-phenyl substitution, which should stabilize the uncyclized iminium ion (e.g. 6 in Scheme 4) raising the barrier to cyclization. Alternatively the $\beta$-phenyl group in 9 may be inhibiting the formation of the initial iminium ion (e.g. 6) in the catalytic cyclic due to the increased electron density at the carbonyl carbon. In contrast, placing a phenyl group at the $\alpha$ position (as in divinyl ketone 15) stabilizes the cyclized allylic cation intermediate 7. This behavior of $\alpha$-substitution promoting the reaction while $\beta$ - substitution inhibits cyclization has been previously noted. ${ }^{15}$ The good yields observed with methyl (11) and dimethyl (12) $\beta$ substituted divinyl ketones (Table 1) are consistent with the notion that extended conjugation of the phenyl group at the $\beta$-position in the uncyclized iminium ion (e.g. 6, Scheme 4) raises the barrier to cyclization more than $\beta$-alkyl substitution. The net effect is that hydroxylamine is an effective catalyst for the cyclization of $\beta$-alkyl substituted $\alpha$-alkoxy divinyl ketones but is not a 
Table 1. Cyclopentenones from hydroxylamine-catalyzed

Nazarov cyclizations. ${ }^{a}$

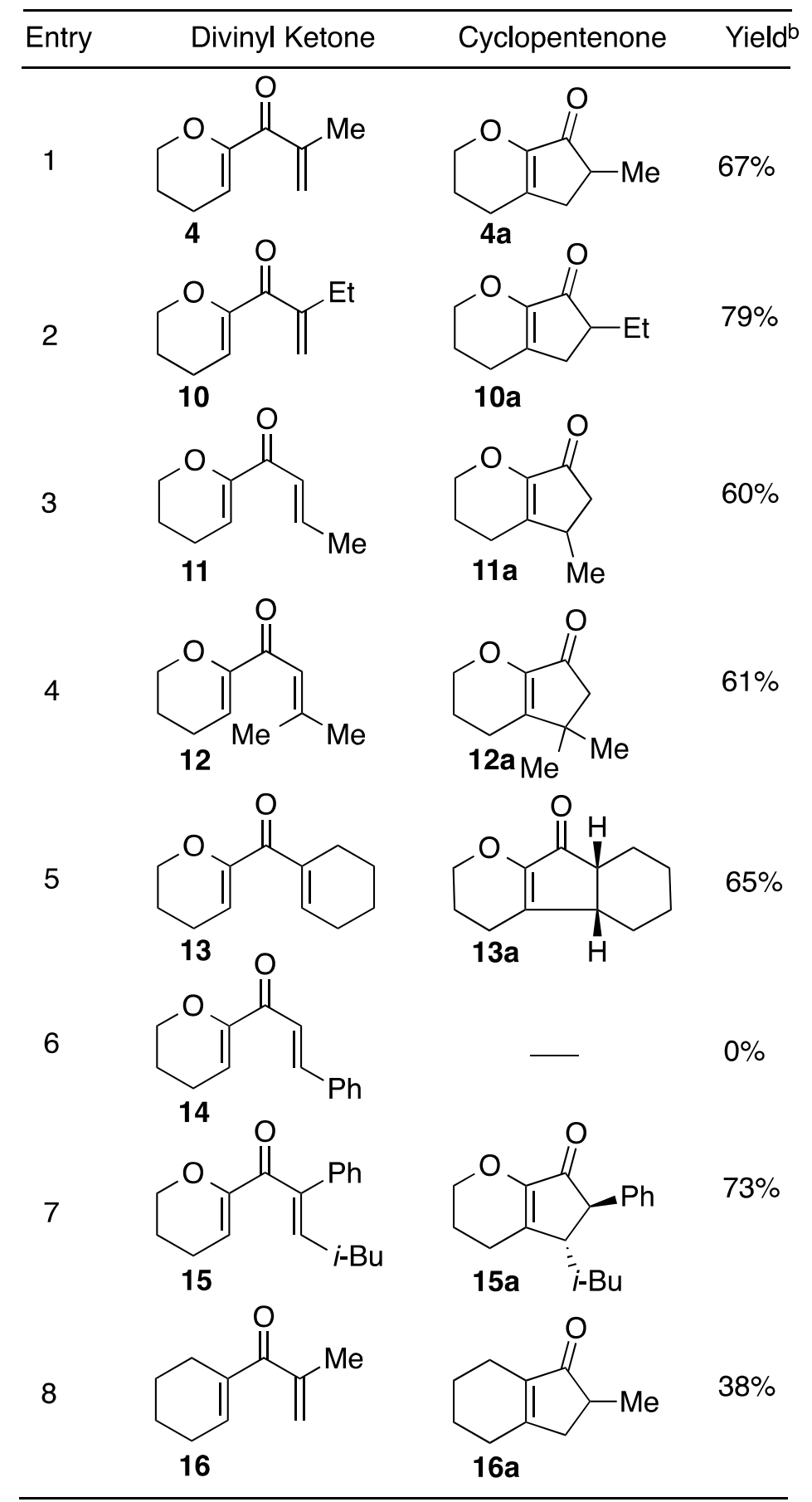

${ }^{a}$ All reactions were performed in ethanol at $\sim 0.2 \mathrm{M}$ with $20 \mathrm{~mol} \%$ hydroxylamine hydrochloride catalyst, at $70^{\circ} \mathrm{C}$. Rxn times $\sim 16 \mathrm{~h} .{ }^{b}$ Isolated by column chromatography. 
strong enough catalyst to overcome the electronic effects of $\beta$ - phenyl substitution. Lewis acid catalysts do not have this limitation and give excellent yields of cyclization products with $\beta$ phenyl substituted divinyl ketones. ${ }^{16}$

In order to determine if the Nazarov cyclization of divinyl ketone 15 was diastereoselective we heated the cyclized product $15 \mathbf{a}$ at $70^{\circ} \mathrm{C}$ with hydroxylamine hydrochloride $\left(20 \mathrm{~mol} \%\right.$ ) in ethan(ol-d) for 16 hours. Analysis by ${ }^{1} \mathrm{H}$ NMR showed the incorporation of three deuterium atoms $(\mathbf{1 5 b}$, Scheme 5) indicating that any cis product formed in the cyclization would have epimerized to the more stable trans isomer under the reaction conditions.

Scheme 5. H-D exchange in cyclization products.
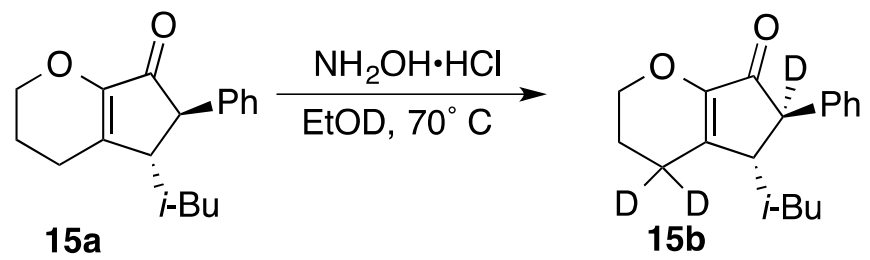

\section{Conclusion}

We have discovered a new catalyst for the Nazarov cyclization of divinyl ketones. The ability of hydroxylamine to catalyze the cyclization is likely due to the $\alpha$-effect, which increases the nucleophilicity of the amine allowing the transient formation of the requisite iminium ion. Our current efforts are being directed at exploring this new catalytic mode for the Nazarov cyclization in order to find iminium ion catalysts that are effective under milder reaction conditions.

\section{Acknowledgements}

ARM gratefully acknowledges financial support of this work from Oberlin College and the NSF (0420717) for funding of a Beowulf computer cluster. We also thank the Mass Spectrometry Center at the University of Akron for the HRMS measurements.

\section{Supplementary data}


Supplementary data (experimental section with procedures and spectroscopic characterization: ${ }^{1} \mathrm{H}$ and ${ }^{13} \mathrm{C}$ NMR, HRMS, of compounds 4a, 10a, 11, 11a, 12a, 13a, 15, 15a, 15b, 16 and 16a; Computational methods, cartesian coordinates and energies for compounds 1-3) with this article can be found in the online version at ....

\section{References and notes}

1. Recent Reviews: (a) West, F.G.; Scadeng, O; Wu, Y.; Fradette, R.J.; Joy, S. Comprehensive Organic Synthesis, $2^{\text {nd }}$ Edition, Editors Knochel,P,; Molander, G., 2014, 827-866. (b) Wenz, D.R.; Read di Alaniz, J. Eur. J. Org. Chem. 2015, 2015, 23-37. (c) Ausran, G.; Bremond, P.; Feuerstein, M.; Marque, S.R.A.; Santelli, M. Tetrahedron 2013, 69, 8325-8348.

2. Review: Vaidya, T.; Eisenberg, R.; Frontier, A.J. ChemCatChem 2011, 3, 1531-1548.

3. Reviews: (a) Di Grandi, M.J. Org. Biomol. Chem. 2014, 12, 5331-5345. (b) Tius, M.A. Chem. Soc. Rev. 2014, 43, 2979-3002.

4. (a) Review: Shimada, N.; Stewart, C.; Tius, M.A. Tetrahedron 2011, 67, 5851-5870. (b) Hutson, G.E.; Turkmen, Y.E.; Rawal, V.H. J. Am. Chem. Soc. 2013, 135, 4988-4991. (c) Xu, Z.; Ren, H.; Wang, L,; Tang, Y. Org. Chem. Front. 2015, 2, 811-814.

5. (a) Review: Grant, T.N.; Rieder, C.J.; West, F.G. Chem. Commun. 2009, 5676-5688. (b) Wu., Y-K.; McDonald, R.; West, F.G. Org. Lett. 2011, 13, 3584-3587. (c) Leboeuf, D.; Gandon, V.; Ciesielski, J.; Frontier, A.J. J. Am. Chem. Soc. 2012, 134, 6296-6308. (b) Petrovic, M.; Scarpi, D.; Fiser, B.; Gomez-Bengoa, E. Eur. J. Org. Chem. 2015, 2015, 3943-3956. (d) Liu, M-Q.; Zhou, A.H.; Jian, S.; Wang, J.-Q.; Ye, L-w. Synthesis 2014, 46, 2161-2167.

6. Applications of Nazarov cyclization in natural product synthesis: (a) Bitar, A.Y.; Frontier, A.J. Org. Lett. 2009, 11, 49-52. b) Zhou, Z.; Tius, M.A. Angew. Chem. Int. Ed. 2015, 54, 6037-6040. (b) Shavartbart, A.; Smith, A.B. J. Am. Chem. Soc. 2014, 136, 870-873. (c) Sudhakar, G.; Satish, K.; Chemistry-A European J. 2015, 21, 6475-6480.

7. Reviews of iminium-ion catalysis: (a) MacMillan, D.W.C. Nature 2008, 455, 304-08; (b) Lelais, G.; MacMillan, D.W.C. Aldrichchimica Acta 2006, 39, 79-87. (c) Jensen, K.L.; Dickmeiss, G.; Jiang, H.; Albrecht, L.; Jørgensen, K. A. Acc. Chem. Res. 2011, 45, 248-264. 
8. (a) Bow, F.W.; Basak, A.K.; Jolit, A.; Vicic, D.A.; Tius, M.A. Org. Lett. 2010, 12, 440443. (b) Tius, M.A.; Chu, C.C; Nieves-Colbert, R.; Tetrahedron Lett. 2001, 42, 24192422. (c) Suarez-Pantiga, S.; Rubio, E.; Alvarez-Rua, C.; Gonzalez, J.M. Org. Lett. 2009, 11, 13-16. (c) Bonderoff, S.A.; Grant, T.N.; West, F.G.; Tremblay, M. Org. Lett. 2013, 15, 2888-2891.

9. $\quad$ Smith, D.A.; Ulmer, C.W. J. Org. Chem 1997, 62, 5110-5115.

10. Cavill, J.L.; Elliot, R.L.; Evans, G.; Jones, I.L.; Platts, J.A.; Ruda, A.M.; Tomkinson, N.C.O. Tetrahedron 2006, 62, 410-421.

11. Edwards, J.O.; Pearson, R.G. J. Am. Chem. Soc. 1962, 84, 16-24.

12. For reversible formation of oximes see: Shriner, R.L.; Fuson, R.C.; Curtin, D.Y. In The Systematic Identification of Organic Compounds; $5^{\text {th }}$ ed., Wiley: New York, 1956; p 250.

13. (a) pKa Hydroxylamine hydrochloride and acetic acid: Haynes, W.M. (ed.) in $C R C$ Handbook of Chemistry and Physics, 95th Edition, CRC Press LLC, Boca Raton: FL, 2014, p. 5-92 and p. 5-94. (b) Estimated pKa of diethylhydroxylamine: Hilal, S.H. in Quantitative Treatment of Solute/Solvent Interactions, Politzer (ed) Elsevier, Amsterdam, 1994, pp. 391-353.

14. The reaction appears to form $\sim 10 \%$ of the double isomer 2-methyl-2,3,3a,4,5,6hexahydro- $1 H$-inden-1-one in addition to 11a.

15. Habermas, K.L.; Denmark, S.E. Org. React. 1994, 45, 1-154.

16. For examples of Lewis acid catalyzed Nazarov cyclizations of $\beta$-phenyl dienones see: (a) Liang, G.; Gradl, S.N.; Trauner, D. Org. Lett. 2003, 5, 4931-4934. (b) Aggarwal, V.K.; Belfield, A.J. Org. Lett. 2003, 5, 5075-5078. (c) He, W.; Sun, X.; Frontier, A.J. J. Am. Chem. Soc. 2003, 125, 14278-14279. 


\section{Legends}

Scheme 1. Diamine Catalysis of $\alpha$-Ketoenones Nazarov Cyclizations.

Scheme 2. Iminium Catalysis of a Divinyl Ketone.

Scheme 3. Nazarov cyclization of activated divinyl ketones.

Scheme 4. Proposed catalytic cycle for hydroxylamine-catalyzed Nazarov cyclizations.

Scheme 5. H-D exchange in cyclization products.

Table 1. Cyclopentenones from hydroxylamine-catalyzed

Nazarov cyclizations. ${ }^{\text {a }}$

\section{Graphical Abstract:}

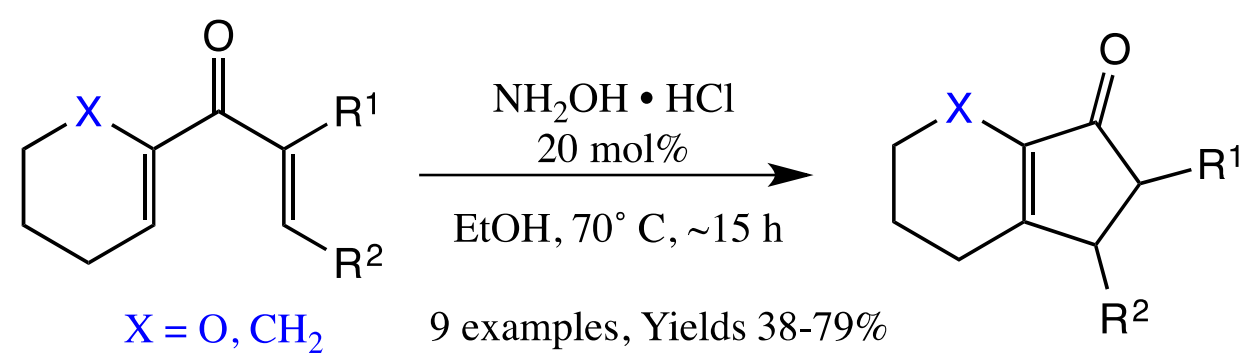

